\title{
X - Band Fractal Microstrip Antenna for Wireless Application
}

\author{
B. Hephzibah Lincy \\ M.E Communication Systems \\ GKM College of Engineering \\ and Technology \\ Chennai - 63, India.
}

\author{
A. Srinivasan \\ Associate Professor/ECE \\ GKM College of Engineering \\ and Technology \\ Chennai - 63, India.
}

\author{
B.Rajalakshmi \\ Assistant Professor/ECE \\ GKM College of Engineering \\ and Technology \\ Chennai -63, India.
}

\begin{abstract}
Wideband application put a new demand on antennas pertaining to size, gain, efficiency, bandwidth and more. This paper presents the design and analysis of fractal antenna which uses the self similarity property of fractal geometry. This unique property is exploited to develop antenna elements that are wideband and compact possessing highly desirable properties. The presented antenna is circle inscribed octagon shaped. Simulation results show that the antenna can be used in $\mathrm{X}$ band frequency range exhibiting wideband properties. Radiation pattern and gain characteristics are also analysed.
\end{abstract}

\section{Key words}

Fractals, Wide Band, Fractal Microstrip Patch Antenna, X band.

\section{INTRODUCTION}

Modern developments in communication systems require antennas with wider bandwidth and smaller dimensions. Demand for such antennas which are smaller in size, low fabrication complexity and low cost has increased in military as well as commercial applications. For conventional antenna if size is less than a quarter wavelength then radiation bandwidth and efficiency is reduced [3]. This problem is overcome by using fractal geometry in designing antennas.

Fractals have self similar shapes and space filling properties that can be subdivided into parts. This property makes the fractal antenna compact and wideband. The different fractal elements of the antenna make it to have different resonances. The presence of discontinuities in the geometry increases the bandwidth and radiation properties of antenna. It also has long electrical lengths that fit into a compact size [8][5].

In this paper a new fractal geometry which is circle in octagon shaped is designed. Antenna parameters for operating frequency of $10 \mathrm{GHz}$, in $\mathrm{X}$ band frequency ranges are analysed and found to exhibit multiple bands. Simulation is done in Ansoft HFSS software and the results are compared.

\section{DESIGN APPROACH}

Fractal microstrip patch antenna is designed based on iterative method [8]. Dimension of each iteration is different. A number of iterations can be performed but considering fractal antenna's compactness only three iterations are performed. Also, in higher iterations there is no significant change in antenna properties [1].
The interior and exterior radius of the octagon, as shown in figure 1 , is given by

$$
\begin{aligned}
& \boldsymbol{r}_{e}=\frac{\boldsymbol{a}}{2} * \sqrt{4+2 \sqrt{2}} \\
& \boldsymbol{r}_{i}=\frac{\boldsymbol{a}}{2} * \sqrt{1+\sqrt{2}}
\end{aligned}
$$

Where,

$$
\begin{aligned}
& \text { a }- \text { side of the octagon } \\
& r_{e}-\text { External radius } \\
& r_{i}-\text { Internal radius }
\end{aligned}
$$

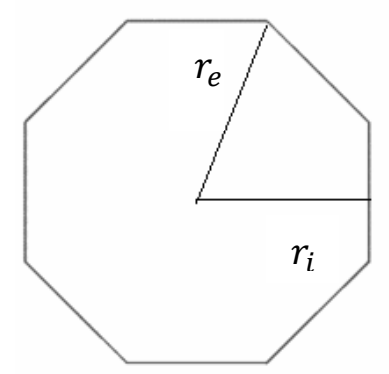

Figure 1: Geometry of Octagonal Sub array

The array factor of the fractal antenna is given by [4],

$$
\boldsymbol{A F}_{p}=\prod_{p=1}^{p} G A\left(\delta^{p-1} \psi\right)
$$

Where,

$$
\begin{aligned}
& \delta \text { - Scaling factor } \\
& \text { P - Level of iteration } \\
& G A \psi \text { - Array Factor Associated with Generating Array }
\end{aligned}
$$

The radius of the circle that is subtracted from the octagon is the interior radius of the octagon. This is repeated till the third iteration is obtained. The side of the first iterative octagon is $a=14.7 \mathrm{~mm}$ and radius of the first inner circle subtracted is $\mathrm{r}=17.8 \mathrm{~mm}$. The three iterative patterns with CPW feed are shown in figure 2 . 


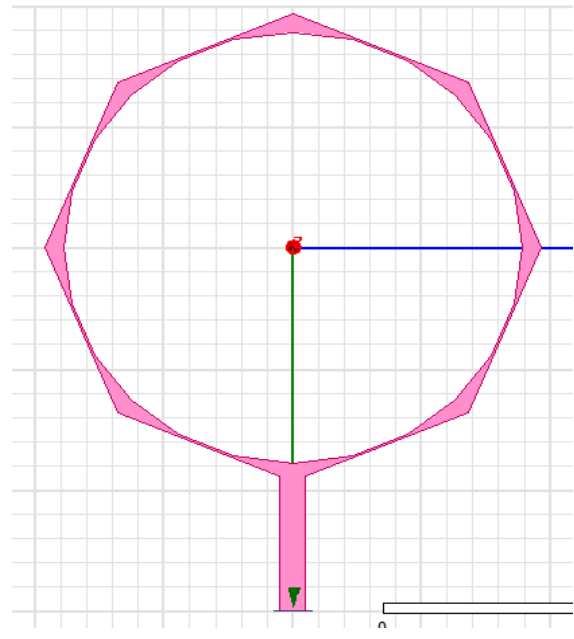

a. First Iteration

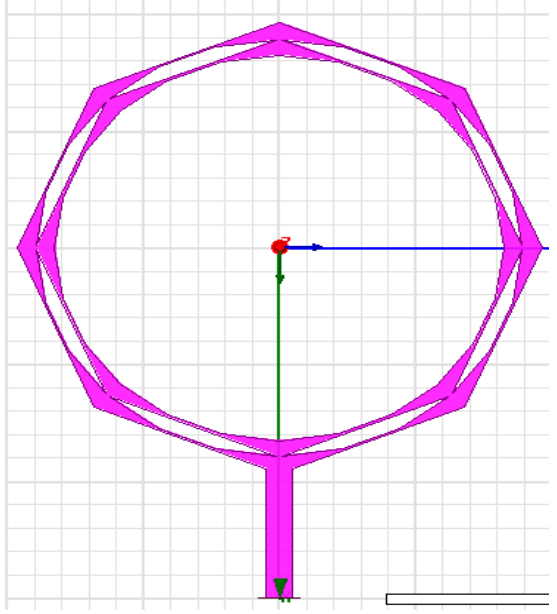

b. Second Iteration

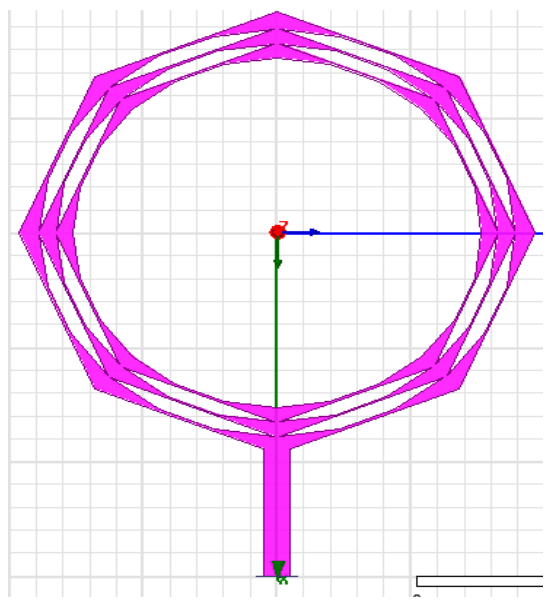

c. Third Iteration

Figure 2: Iterations with CPW Feed
The dimensions of the ground plane is $60 \times 60 \mathrm{~mm}$. The antenna is placed on fr 4 substrate with $\epsilon_{r}=4.4$ and thickness $0.25 \mathrm{~mm}$. The substrate is placed over a ground plane of perfect conductor with thickness $1 \mathrm{~mm}$. CPW feed of length $11.2 \mathrm{~mm}$ and width $2 \mathrm{~mm}$ is given to the patch. CPW feed is used because it exhibits broad bandwidth matching, coplanar capability low dispersion at higher frequencies and ease of design and fabrication [2]. Feed dimensions are selected to obtain impedance of $50 \mathrm{ohms}$ for proper impedance matching. A wave port is designed at the end of the feed line.

\section{SIMULATION RESULTS AND DISCUSSION}

Antenna is designed using High Frequency Structured Simulator (HFSS) software. The patch is a perfect - E conductor. The third iteration is found to have improved antenna parameters compared to the first and second. Return loss plots for second and third iterations in the X-band frequency range of $8 \mathrm{GHz}-12 \mathrm{GHz}$ operating at $10 \mathrm{GHz}$ is shown in figure 3 . It is observed that the return loss characteristics reduce as the number of iteration increase.

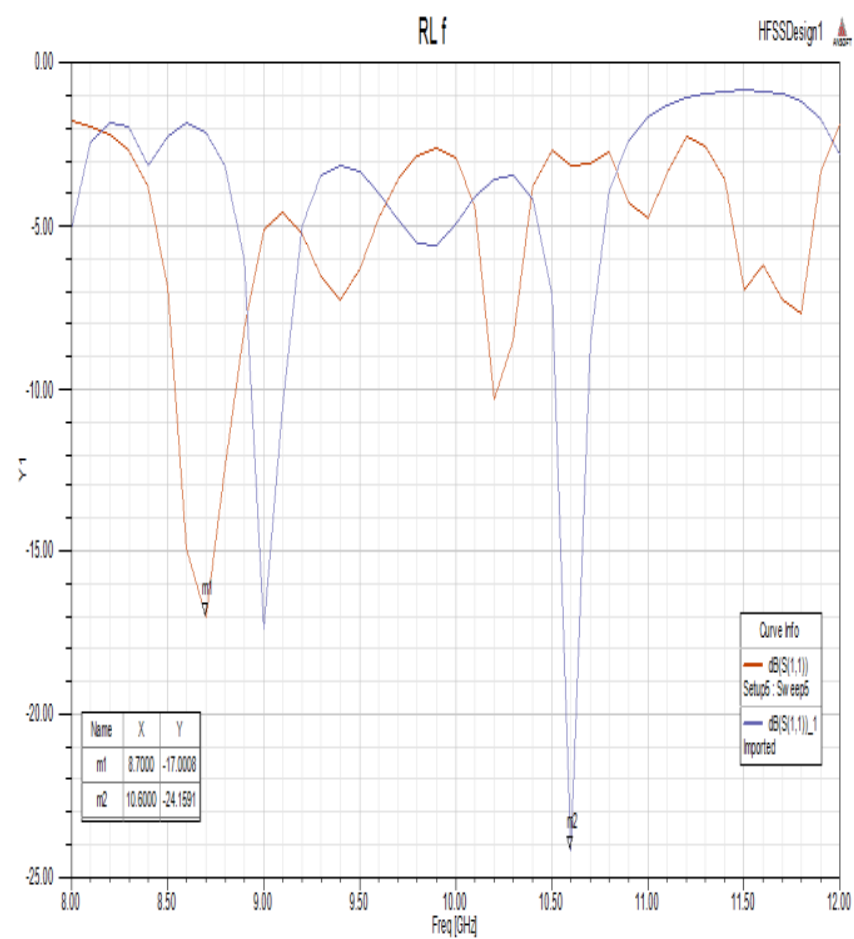

Figure 3: Return Loss Plot of second and third iteration

Gain Vs frequency plot of different iterations shown in figure 4. In $8 \mathrm{GHz}-12 \mathrm{GHz}$, a wide bandwidth of $3.2112 \mathrm{GHz}$ is obtained in the range of $8.53 \mathrm{GHz}-11.7470 \mathrm{GHz}$ for the third iteration. It is observed that wideband characteristics have improved, as number of iteration increase, due to the current along its edges. 


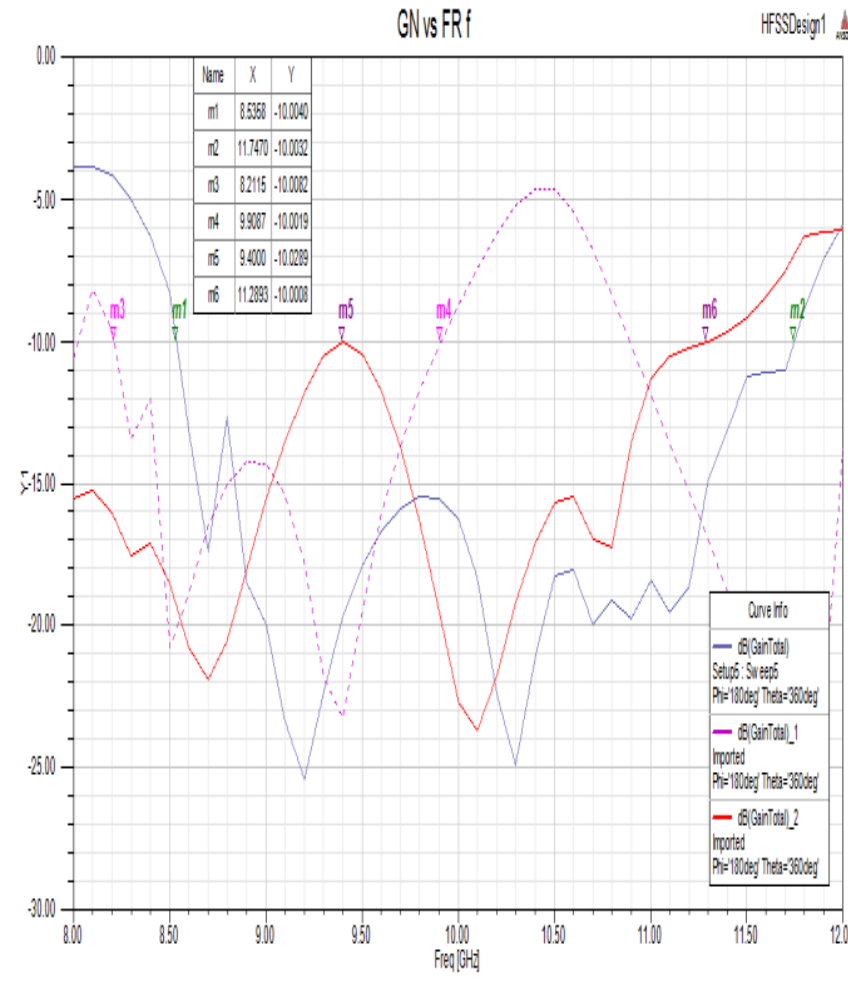

Figure 4: Gain Vs Frequency Plot

Radiation pattern is shown in figure 5. It is observed that the number of side lobes is reduced in the third iteration. 3-D Radiation Pattern of third iteration is shown in figure 6.

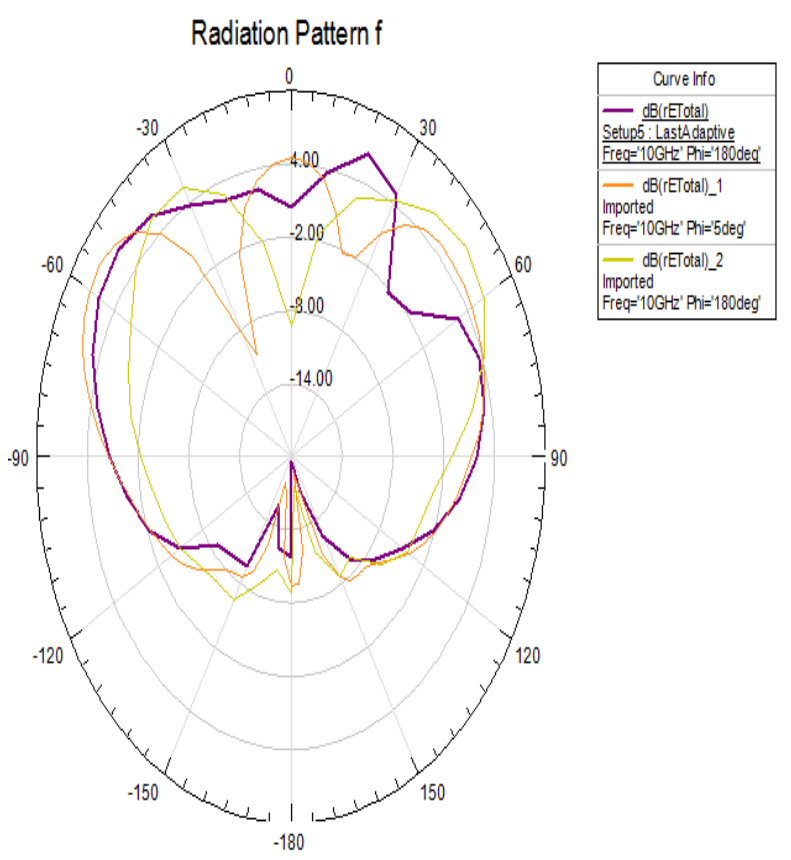

Figure 5: Radiation Pattern
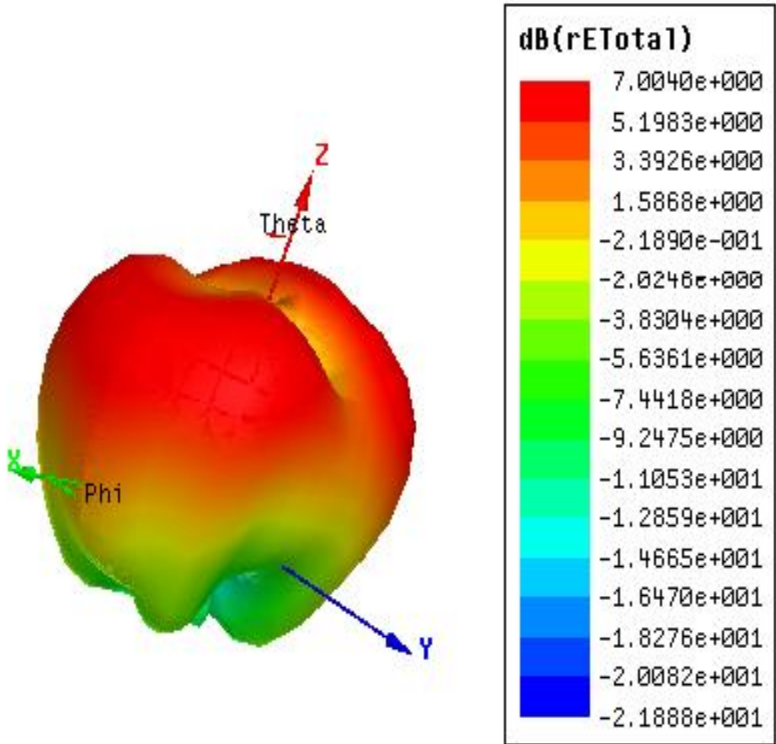

Figure 6: Third Iteration 3-D Radiation Pattern

\section{CONCLUSION}

The new fractal antenna is designed and simulated using HFSS software. Results in X band frequency range of $8 \mathrm{GHz}-12 \mathrm{GHz}$ has been analysed. It is observed that the third iteration of the fractal antenna exhibits good wideband characteristics, which can be used in wireless application such as, terrestrial broadband, armature radio and satellite communication. This microstrip antenna assures simplicity in design and fabrication.

\section{ACKNOLEDGEMENT}

We the authors would like to thank the Registrar Dr.K.O.Joseph, Prinicipal Dr.N.Ramaraj and HOD Dr.D.Balasubramanian for their constant encouragement rendered in completion of this project with their constant technical support and invaluable guidance.

\section{REFERENCES}

[1] Ayachi Ajey, Shambavi and Zachariah C Alex, "Design and Analysis of Fractal Antenna for UWB Applications", 2012 IEEE Students' Conference on Electrical Electronics and Computer Science.

[2] Rajkumar, P. Malathi, "On The Design of CPW-Fed Ultra Wideband Triangular Wheel Shape Fractal Antenna", Rajkumar, P. Malathi, International Journal of Microwave and Optical Technology, Vol.5, No.2, March 2010.

[3] Raj Kumar, J P Shinde, P N Shinde, M D Uplane, "On the design of CPW-Fed Square Octal Shaped Fractal UWB Antenna”, IEEE 2009.

[4] Abolfazl Azari, "Super Wideband Fractal Antenna Design”, 2009 IEEE.

[5] Kulbir Singh, Vinit Grewal and Rajiv Saxena, "Fractal Antenna: A Noval Miniaturization technique for Wireless Communications", International Journal of Recent Trends in Engineering, Vol 2, No. 5, Nov 2009. 
[6] A. Anzari, J. Rowhani, "Ultra Wideband Fractal Microstrip Antenna Design", Progress in Electromagnetics Research c vol.2, 7-12, 2008.

[7] C. A. Balanis, Antenna Theory: Analysis and Design, $3^{\text {rd }}$. Hoboken, NJ: Wiley, 2005.
[8] D.H. Werner and S. Ganguly, 'An Overview of Fractal Antenna Engineering Research", IEEE, Antenna and Propagation Magazine, Vol 45, No. 1,38 - 57, 2003

[9] J.P. Gianvittorio and Y.R. Samii, "Fractal Antennas: A Noval Antenna Miniaturization Technique and Application", IEEE Antennas Propag. Mag., vol. 44, No. 1, Feb. 2002. 